THURSDAY, MAY 16,1872

\section{EXAMINATIONS IN TECHNOLOGY}

$\mathrm{N}^{\circ}$

subject has been more talked about of late years than Technical Education. No term has been more vaguely or indefinitely used than this, even in education, that region of loose definition; yet it cannot be doubted that at the present time no subject is of more vital importance to this country, to enable it to maintain its manufacturing position, than a general diffusion of sound technical knowledge-a knowledge, that is, which rests on a thorough apprehension of the scientific principles which lie at the root of the various arts and manufacturing processes.

Bacon, in the first of his "General Aphorisms for Interpreting Nature and Extending the Empire of Man over Creation," says :- "Man, who is the servant and interpreter of Nature, can act and understand no further than he has, either in operation or in contemplation, observed of the method and order of Nature." And he proceeds, "neither the hand without instruments, nor the unassisted understanding, can do much ; they both require helps, the understanding no less than the hand, to fit them for business. .... . The knowledge and power of man are coincident ; for whilst ignorant of causes he can produce no effects, nor is Nature to be conquered but by submission. And that which in speculation stands for the cause, is what in practice stands for the rule." The men of science of our day are not open to Bacon's rebuke to the mathematician, the physician, and the chemist of his day, that they were concerned in the works of Nature, but all of them superficially and to little purpose. Day by day sees them conquering Nature by submission. Are the thousands engaged in our manufacturing industries capable of taking advantage of their conquests? How painfully true with respect to them still are his words, written some 250 years ago, "The works hitherto discovered are owing rather to accident and trial th in to the sciences."

Playfair remarks on this, "One of the considerations which appear to have impressed Bacon's mind most forcibly was the vagueness and uncertainty of all the physical speculations existing in his time, and the entire want of connection between the Sciences and the Arts." The vagueness and uncertainty of physical speculation is rapidly clearing away. Is the connection between the Sciences and the Arts as rapidly being cemented? We fear not. The world has become imbued with the truth of Bacon's saying, that "in works men can do no more than put natural bodies together and take them asunder; all the rest is performed by the internal operations of Nature." But how little is the order of Nature which should reguiate this putting together and taking asunder understood in our workshops: How much is trusted to trial and error! How little is the store of knowledge accumulated by our men of science drawn upon! How great is the waste of our resources!

We therefore hail with satisfaction a scheme of technological examinations proposed by Captain Donnelly, R.E., which the Society of Arts has adopted on the recommen-

VOL. VI. dation of an able committee of scientific and professional men to whom it was referred, and which it appears, from a paper lately issued, the Society intends to carry out if the requisite support be forthcoming.

The proposal of Captain Donnelly is briefly that every year the Society of Arts should arrange for the examination in the science and technology of certain arts and manufactures. A committee qualified to advise on the subject is to prepare a syllabus of the examination in each branch of industry. It is an instruction to them "that it is essential that the candidate should possess, on the one hand, such an elementary knowledge, at least of science, as will prove that he understands the scientific principles of which his art is an application; and, on the other hand, such a knowledge of the application of those principles in his trade, as will show that he is practically conversant with the various processes and manipulations of the factory or workshop. The theoretical knowledge must not be a mere 'cram' of empirical dicta, nor the practical knowledge a mere committal to memory of descriptions of manufactures picked up from text-books." This instruction shows that the technology which it is proposed to cultivate by means of these examinations is thoroughly sound.

The requirements from a candidate fall naturally under three heads. We have first those branches of abstract science which are involved in the special industry under consideration; secondly, the special applications of those abstract or general sciences to that industry; and lastly, a practical knowledge of the machinery, processes, and manipulation.

The examinations of the Science and Art Department, which are now held pretty generally in all parts of the kingdom, and which can be extended to any place which desires to avail itself of them, by the simple process of forming a local committee of superintendence, provide the ready means of testing the candidates' knowledge of any branches of general science. It is only necessary then to determine what branches of science are the foundation of the technology of any industry, and to specify the examination which the candidate shall pass for each grade of certificate. The Society of Arts, working in concert with the Science and Art Department, proposes to avail itself therefore of these examinations to determine the candidate's knowledge of pure science.

As respects the technology or special applications of general science, the committee will prepare a syllabus for each industry. And the examination in these matters will also be conducted by means of the local committees after the general science examinations, the papers of questions being prepared by special examiners, to whom the answers will be submitted. Finally, the candidate's practical knowledge will be ascertained by a return of his employment in the factory or workshop, giving his rate of wages, \&c., certified by his employer, somewhat in the form of the return required from candidates for Whitworth Scholarships. No more reliable criterion of a candidate's practical knowledge could be afforded than this. It is in the workshop, and in the workshop alone, that a true practical education can be obtained. It is a great advantage that this scheme wholly avoids running counter to the just susceptibilities of our manufacturers on this cardinal doctrine, and pro- 
poses simply to strengthen and ennoble this practical education by combining it with sound scientific instruction. The whole machinery of the examination is simple, effective, and, by means of local co operation-a machinery which already exists-readily applicable, at small cost, to all parts of the kingdom.

The examinations are to be adapted to three grades of certificates : an elementary, or "Workman's" certificate ; an advanced, or "Foreman's" certificate; and an honours, or "Manager's" certificate.

No syllabus has yet been issued, but we have seen the syllabus for paper manufacture, which, though not finally adopted by the committee, is in a forward state. How many candidates will come up to the mark? We fear but few. There is no use shutting our eyes to the fact. Among manufacturers how many are there who could pass a fair examination in the Science and Technology of their trade? And yet the committee have not pitched their standard too high. One great benefit-if no other - will be conferred by these committees. They will show at least what ought to be known.

As a commencement, Captain Donnelly proposes that those industries should be taken for examination which form the subjects of the Annual International Exhibitions, and that the Royal Commissioners for the Exhibition of $185 \mathrm{I}$ should be asked to provide the requisite funds. The committee endorse Captain Donnelly's view, and think that the Council of the Society of Arts "may find it advantageous to include those Arts and Manufactures." We trust that it may be found practicable to include annually many more, and that this important movement will not be left to depend on the Annual Exhibitions alone, however ready the ComInissioners may be to support it. It is for the manufacturers of this ountry, for the City Companies, and the large towns, whose very existence depends on their manufacturing supremacy, to come forward and aid this important work, and do for their several industries what Sir Joseph Whitworth has done for mechanical engineering by his noble endowment.

By this means a stimulus will be given to the extension of scientific instruction; an aim and organisation afforded of which it stands in much need; and a decided step taken to re-establish our manufacturing supremacy, which, in consequence of the superior educational position of our continental rivals, is now trembling in the balance.

\section{WATTS'S DICTIONARY OF CHEMISTRY}

$A$ Dictionary of Chemistry. By Henry Watts, F.R.S., B.A., \&c. Supplement. (Longmans, Green, and Co., London, r872.)

F NGLISH chemists will hail with gladness the appearance of the supplemental volume to "Watts's Dictionary." It was evident almost before the completion of the last volume of the original work, that a supplementary volume would be required very shortly. In these days of progress chemical books are quickly left behind, and it needs energetic measures for our literature to keep pace with fresh chemical discoveries. Chemistry has much to be thankful for at the hands of Mr. Watts. The present volume brings up our knowledge to the end of I 869, and also includes several additions, corrections, \&c., which have appeared in 1870 and $187 \mathrm{r}$. The scope of this volume is, as in former volumes, sufficiently wide; the contents are not entirely confined to chemistry, but include articles on electricity, heat, light, \&c. The connection between these subjects and chemistry is so close that no book would be perfect which did not enter into and explain some of the effects caused by these forces. The plan of "Watts's Dictionary" is too well known to require any comment. The present volume is strictly a continuation of the former ones; and, as time rolls on, other supplemental volumes will be required to make this record of chemical history complete. As it is, we now possess in "Watts's Dictionary" a complete account of chemical discovery up to the end of 1869 ; and in the abstracts of foreign papers published by the Chemical Society we have a contemporaneous record of all new facts, beginning, however, with the year 1871. It is, perhaps, unfortunate either that Mr. Watts did not bring out his Supplement one year later, or that the Chemical Society did not commence their extremely valuable work one year earlier. At the present time, therefore, we have one year to a certain extent unrepresented. We have, however, gained a great step ; instead of having to wait two or three years for the appearance of the "Jahresbericht," we have now the abstracts of foreign papers a month or so after their publication. It is worthy of remark that Mr. Watts's dictionary has outstripped the "Jahresbericht:" the third volume of which, for 1869 , has not yet appeared. The author has fortunately succeeded in obtaining the assistance of some of the former contributors to his work, thus Prof. C. G. Foster contributes two very clear articles on recent discoveries in electricity and heat, whilst Prof. Roscoe has written the articles on "Light and on Spectrum Analysis," which give a very excellent résumé of the work done in these branches of science, and which, perhaps, might have been lengthened with advantage. The article on "Proteids" is written by Prof. M. Foster, whose name is a sufficient guarantee for its excellence. Dr. Paul and Mr. Wanklyn have also contributed to the Supplement, the latter having written on acetic ether (in part), on butyl alcohols, \&c. The only possible objection to this outside help is that, in some instances, undue prominence may be given to certain of the author's theories or remarks, to the comparative overlooking or slighting of the work of other chemists. We must not, however, omit to speak in the highest terms of many of the articles contributed by Mr. Watts himself, such as the extremely clear and succinct account of the aromatic series as explained by Kékule's hypothesis, the article "On Atomicity," and many others too numerous to mention. We cannot give the volume greater praise than by saying it is quite equal to the former productions of the author. Since the publication of the last volume, the chemistry of the aromatic series seems to have usurped the principal attention of chemists, as we find by long articles on benzine, on its derivatives and homologues, no less than forty-five pages being thus occupied; then again the substitution derivatives of benzoic acid and of phenol occupy a considerable space. Another subject which seems to have attracted a considerable amount of attention, and to have yielded very interesting results, is that of the alcohol 